\title{
Application of CLN-IgG/Pritumumab against COVID-19 Infectivity from the Aspect of Tumor-PIVIEMT Scheme
}

\author{
Hugwil AV* \\ HIHIMSA Foundation, USA
}

*Corresponding author: Albert V Hugwil, PhD, HIHIMSA Foundation, Oceanside CA 92054, USA, Tel: 7604585500; Email: alhugwil@gmail.com

\section{Review Article}

Volume 5 Issue 1

Received Date: February 06, 2021

Published Date: February 25, 2021

DOI: $10.23880 /$ oajco-16000169

\section{Abstract}

The touch/tactile sensor PIEZ01/2 and vimentin network is the critical conduit for COVID-19 virus infectivity. Coordination of PIEZ01/2 and vimentin network in regard to EMT/MET which is actual accordance of PIVEMT is critical for stem cell sustenance and wound healing of the injured cells and tissues in inflammation. On the contrary PIVIEMT discordance, deteriorated PIEZ01/2-Vimentin network, provokes pathogenic symptoms such as severe autoimmunopathies. From this aspect imminent treatment is necessary to recuperate the patients from onset of pathogens and/or neoplasms by use of chaperonic antibody that is able to restore/resile the pathogenic PIVIEMT as seen in the clinical trials against brain tumor patients with repetitive administration of the natural human monoclonal antibody CLN-IgG/Pritumumab. Targeting the virus conduit with the chaperonic antibody is highly expected for not only shutting down the virus infectivity but also augmentation of the antibody-directed vaccination against virus propagation.

Keywords: Anti-Cancer Antibody; Human monoclonal antibody ClN-IgG/Pritumumab; Idiotypic antibody; Vimentinepitope; EMT/MET; Cancer Stem Cell; Prion-amyloid; Brain Tumor; COVID-19

Abbreviations: PIVIEMT: PIEZO1/2-Vimentin Coordination with regard to EMT/MET; vipidam: Vimentin Prionogenic Idiotope Determining Amino Acid Motif; DACSC: Dichotomous Aspect of Cancer Stem Cell; EMT: Epithelial-MesenchymalTransition; MET: Mesenchymal-Epithelial-Transition; CSC: Cancer Stem Cell; NSC: Normal Stem Cell; IIT: Idiotope Image Transmission; TME: Tumor Microenvironment; CR: Complete Remission; PR: Partial Remission.

\section{Introduction}

In spite of the earnest contribution of biomedical challenge against COVID-19 contagion, we have not attained any certainty to end the pandemic. Vaccines distributions targeting the virus spike protein are getting more available, however the infectious rate and mortality do not seem to be waning. In this connection the natural antibodies in the blood plasma from the convalescent and /or recovering patients [1,2] of COVID-19 signed the saving severe COVID-19 ill patients. However the very rare antibody that led the patient into recuperation showed quick clearance from their blood plasmas [3]. In this report author presents an application of the natural human monoclonal antibody CLN-IgG/ Pritumumab aiming at the attenuation of virus infectivity. CLN-IgG/Pritumumab was subjected in clinical trials for brain tumor patients as of the antibody-directed vaccination toward vipidam, a vimentin epitope, from the aspect of idiotope image transmission of the idiotypic antibody network $[4,5]$. From clinical trials of CLN-IgG/Pritumumab (a natural human monoclonal antibody) targeting vipidam in repetitive administration into brain tumor patients resulted in a remarkable response with $\mathrm{CR}+\mathrm{PR}>28.5 \%$ without severe adverse reactions [6-9]. This result indicated that targeting vimentin was the critical point for cancer therapy. 


\section{Open Access Journal of Cancer \& Oncology}

On the other hand PIEZ01/2 touch/tactile ion channel was identified [10] and its tertiary structure has been extensively studied [11]. One of functions of PIEZO1/2 is deeply linked with nociception and proprioception [12] via EMT (Epithelial-Mesenchymal-Transition)/MET (MesenchymalEpithelial- Transition) [13]. Therefore coordination of PIEZO and vimentin involves in pain and anxiety via mechanosensation response [14].

Author provides in this report the PIVIEMT scheme which presents a constellation of PIEZ01/2-Vimentin network showing how cancer stem cell could be reversed into normal stem cell owing to recuperation of cancer-niche cells towards normal-niche cells via resilience of the destressing vimentin network from distressed vipidam. And this scheme indicates how CLN-IgG/Pritmumab could be a potent antibody-directed vaccination against COVID-19 by virtue of the PIVIEMT tumbler. PIVIEMT stands for PIEZOVimentin coordination regarding to EMT/MET [15-24].

\section{Targeting PIEZ01/2 is Indicating Therapeutic Potency of Cancers}

PIEZ01/2's 3-D structure was determined and it showed the tribune blade structure on the cell plasma membrane of almost all kind of somatic cells [11]. PIEZO2 was especially expressed on the neural cells (Neuron and Glia cell) and functioned as an ion channel (e.g. $\mathrm{Ca}+\mathrm{Mg}+/ \mathrm{Zn}+$ channel)
[11]. Augmented PIEZ01/2 was found in several cancer/ tumors including glioma [25] and their function for CSC was to adapt to severe stressful environments under abnormal hypoxia, osmosis, shear stress, hormone response, DNA damage etc. Hyper-nociception/proprioception of the cells/tissues is a big concern with regards to malignant cancer/tumor invasion and metastasis via EMT/MET [26]. In addition hypersensitivity of PIEZO1/2 links to tumor immunity [27], ageing [28], and cholesterol metabolism [29]. Onset of COVID-19 infection indicated PIEZO1/2 expression is linked with cellular senescence [30], vasculo-cardiopathy [31] and age-related neurodegenerative diseases [32].

\section{The Scheme of PIVIEMT Explaining the Regression of Malignant Tumor by Means of Repetitive Administration of Anti-Vipidam Natural Human Monoclonal Antibody CLN- IgG/Pritumumab}

Author reported on the analgesic activity (antinociceptive/anti-proprioceptive) of CLN-IgG/Pritumumab which was found in the course of the medical application of CLN-IgG/Pritumumab as an anti-cancer antibody to human Brain Tumors (Table 1). Analgesics are chemical compounds indicating the links of anti-nociception/anti-proprioception, anti-inflammation, anti-ageing, and anti-carcinogenesis by means of regulation of EMT [33].

\begin{tabular}{|c|c|c|c|}
\hline Compound & Doses (mg/kg, i.v.) & No. of animals & Writhing counts (\%) \\
\hline Control & 0 & 10 & $13.3 \pm 1.6(100)$ \\
\hline \multirow{3}{*}{ Pritumumab } & 0.2 & 10 & $10.1 \pm 2.5(76)$ \\
\cline { 2 - 4 } & 1 & 10 & $9.7 \pm 1.7(73)$ \\
\cline { 2 - 4 } & 2 & 10 & $5.7 \pm 1.7(43)^{* *}$ \\
\hline
\end{tabular}

Table 1: Effect of CLN-IgG/Pritumumab on Analgesic Activity in Mice with The Method of Acetic acid-induced Writhing Test. Each value represents the mean \pm S.E. ( ): relative value.

**: significantly different from control at $\mathrm{P}<0.01$. The test was carried out under GLP.

The analgesic activity of CLN-IgG/Pritumumab was measured by acetic acid-induced writhing in mice with CLN-IgG/Pritumumab administered intravenously through the tail. A single shot with $2 \mathrm{mg} / \mathrm{kg}$ of CLN-IgG/Pritumumab showed dramatic analgesic activity which also indicated anti-nociceptive and anti-inflammatory activity with the equivalent dosage of an opioid e.g. Morphine, Pentazocine, Nalbuphine (Narcotics)). This effect was much higher compared to other NSAID conventional analgesic reagents with 10-times for indomethacin and 100-times for Aspirin. The analgesic effect of CLN-IgG/Pritumumab was inferred by desensitization of PIEZ01/2, which regulates mechanotransduction signaling pathway via the discordance of PIVIEMT.
PIVIEMT stands for PIEZ01/2-Vimentin coordination with regard to EMT/MET cellular phase transitions. The regulation of PIEZ01/2 function led to anti-tumorigenesis. In fact inhibition of PIEZ01/2 with the spider venom GsMTx-4 showed tumor regression. Many analgesics possess cancer/ tumor suppressive activity (e.g. Jatrophane, a diterpenoid from the plant Euphorbiaceae is an example of folk medicine possessing anti-nociception and anti-virus effects followed by blocking aggressive metastasis of malignant cells and virus infectivity accompanied by modulation on EMT/MET $[34,35])$. On the other hand vimentin and its networking is a hallmark of EMT/MET. Therefore it's highly expected that the intervention on PIVIEMT by the repetitive administration of CLN-IgG/Pritumumab on the aberrant sensation of 


\section{Open Access Journal of Cancer \& Oncology}

mechanotransduction in malignant cells may evoke the resilience of distressed vimentin networks via augmentation of chaperonic Abs (proteostasis) [8] (Figure 1). Furthermore vimentin plays a role in the sustenance of CSC so that the administration of CLN- IgG/Pritumumab accounts for the regression of malignancy through a certain reprogramming mechanism of CSC into non-invasive dormant cancer/tumor cells in MET. Moreover we knew repetitive administration of CLN-IgG/Pritumumab to brain tumor patients evoked augmented Ab3 that possesses the same antigenicity toward vipidam. Good responders in complete remission and partial remission (CR-PR) to Pritumumab therapy showed the augmentation of CLN-IgG/Pritumumab via idiotope image transmission (IIT) in conjunction with circaseptan rhythms [36] (Figure 2). The IIT seemed to evoke B-cell Tertiary Lymphoid Structures (TLS) in the primary cancer patients [37]. Targeting vipidam antibody-directed vaccination can also be expected to act against COVID-19 infectivity which depends on distressed PIVIEMT [38].

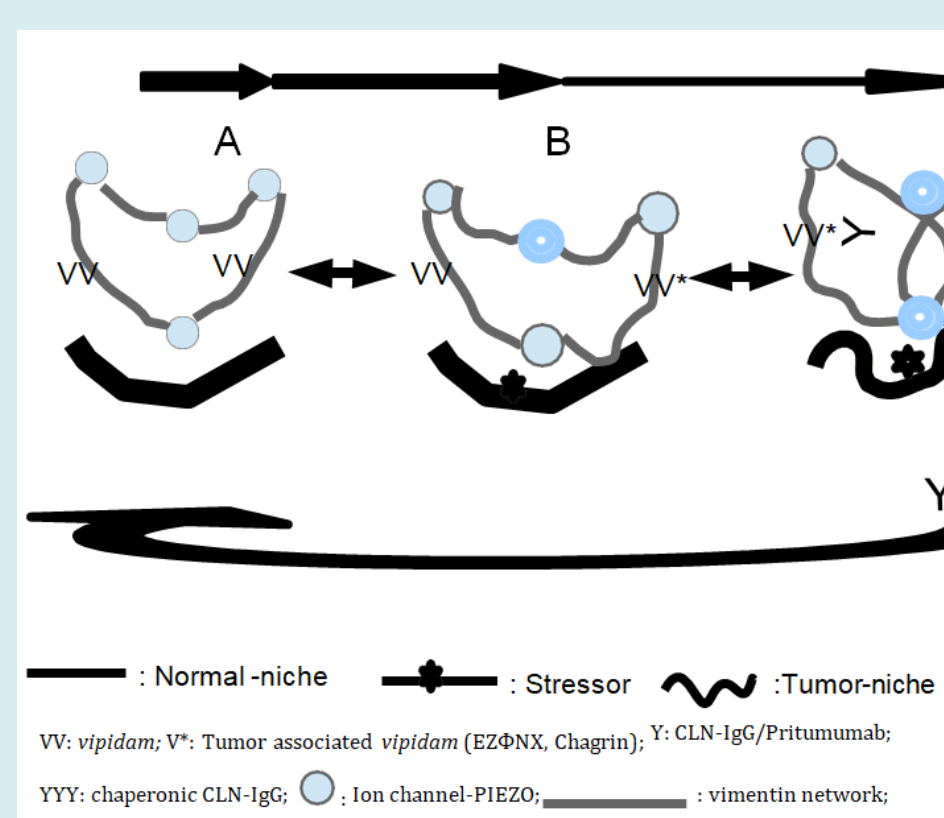

: Putative PIEZO amyloid

Figure 1: The scheme of PIVIEMT tumbler explaining regression of malignant tumor by the resilience of tumor-PIVIEMT by means of repetitive administration of anti-vipidam natural human monoclonal antibody CLN-IgG/Pritumumab.

A-stage: A conceptual image of PIVIEMT in existing networks of idiotope image transmission (IIT) in idiotype antibody networks. PIVIEMT is designated as a tumbler form which cells/tissues respond in the extra-cellular environment (Normal-niche in stromal milieu) via cyclic ion channel flux. Coordination of PIEZO-Vimentin (PIVIEMT accordance) network happens quickly in changing environments by means of tactile sensing of PIEZO leading to cell fate accompanied by EMT/MET. PIEZO-Vimentin network in the cell forms tumbler-like integrated-architecture (tumbler tensigrity) corresponding to the cyclic ion flux that is able to respond to the unprecedented change of the cellular microenvironment (niche) in regards to nociception/proprioception which is sensitized by mechanical stressors and then provokes EMT/MET. A constellation of PIEZO-Vimentin network is schematized in this figure.
B-stage: Vipidam is carried over on the segment $16-20$ aa in Coil2B vimentin (designated with the EZ $\Phi N X$ motif nicknamed "Chagrin") that is transmitted from generation to generation in stem cell renewal [9]. A stress trope transmits via inter/intra cellular PIEZO-Vimentin networks by means of a conduit of prion-amyloidogenesis of vimentin in PIVIEMT. Under severe stress (including intrinsic stress by the over expression of oncogene products), vipidam shifts into its liquid-droplet phase (= coacervation) acquiring prion-like properties and then it represents its antigenicity to immune surveillance effector cells (Topomissive). Configurational shift of PIVIEMT (e.g. from fibril to cage) influences cellular tensigrity which is linked to cell stiffness and/or pliability of the vimentin-associated cytoskeletal protein networks leading to cell hyperplasia accompanied by cell shape change fitting for the cell's mobility through a stressful niche 


\section{Open Access Journal of Cancer \& Oncology}

in the in flammage- induced deteriorated architecture of extra-cellular matrix (ECM). The tensigrity of PIVIEMT is abrogated in the event of tumorigenesis when the cell needs to adapt to the contorted/distressed milieu with neoplastic transformation of the cell.

C-stage: In tumorigenesis PIVIEMT echoed/reflected the contorted/distressed ECM toward the inner molecular prionogenic motif vipidam vice versa. Acquisition of cell motility by means of cell morphological change (=transformation) is also linked to cancer stem cell sustenance and apoptosis resistance in tumor invasion and metastasis with aberrant tumor-associated EMT/ MET. Most all of the proteins in a proteome possess the tendency to form amyloid, which have the physicochemical properties of liquid-droplets and liquid-liquid phase separation (=coacervatogenesis). The biological function of the coacervation of polypeptides has shed light on mRNA stabilization at the sites of RNA processing in the spliceosome, a stress-induced membrane-less organelle (e.g. Stress Granule, nucleoli), and in hetero-chromatin. A tumor microenvironment (T-niche) under severe stress (in this report, I focus on mechanical stress only) provokes a tumor-associated vipidam segment's topological change to respond to the force caused by the stressors, which actuates stress signals (Topomissive) toward the immune surveillance system (e.g. a cell losing its cellular polarity through elimination by immune surveillance). Deterioration of PIEZO-Vimentin coordination (PIVIEMT discordance) provokes the aberration of PIVIEMT resiliency and consequently transmits the stress trope (EZФNX, "Chagrin") over an open IIT network leading to in flammation-associated cellular ageing (inflammage), which accelerates cellular senescence and tumorigenesis. Intervention by use of a vipidam specific antibody such as CLN-IgG/Pritumumab to the amyloidosis of PIVIEMT will facilitate anti-inflammage (=Senolytics/Senostatics), antiage related neurodegeneration, anti-tumorigenesis, and blocks virus infectivity by means of the reversion of PIVIEMT discordance to normal tensigrity for organogenesis via chaperonic antibody-directed vaccination (Figure 2).

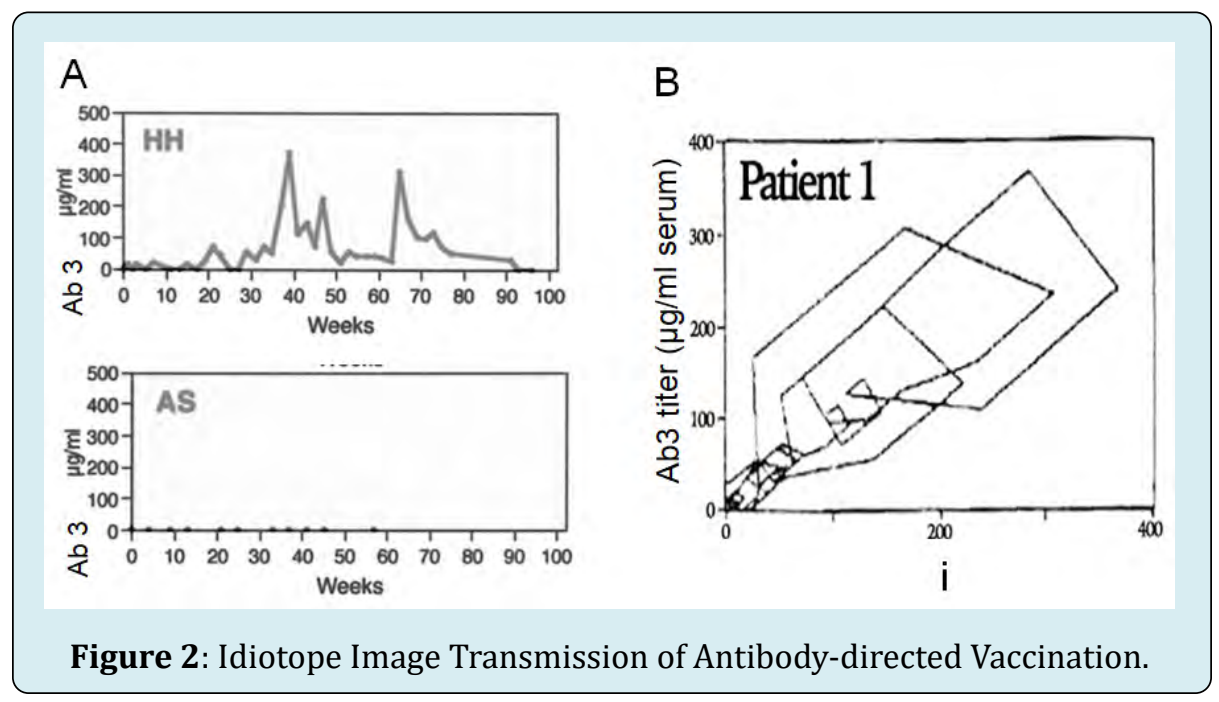

Figure 2 shows Chaotic attractor for the paratope image of anti-anti-idiotypic antibody (Ab3) found in the serum of malignant glioma patients who showed good response to the repetitive administration of CLN-IgG/Pritumumab (Ab1).

Brain tumor patients received $1 \mathrm{mg}$ CLN-IgG/ Pritumumab (Ab1) twice a week for the duration indicated in the horizontal axes of Figure 2A. The concentration of CLN-IgG/Pritumumab in the patient's serum was measured intermittently two times in a week by use of the anti-paratactic idiotypic antibody, murine Idio-33 Ab. The concentration of Ab3 was measured from the amount of IgG corresponding to that of CLN-IgG/Pritumumab calculated from the dosedependent curve in ELISA with the Idio-33 coated micro-titer plates in the presence of $2 \mathrm{M} \mathrm{NaCl}+5 \mathrm{M}$ Urea. The aperiodic augmentation of $\mathrm{Ab} 3$ was observed in the cases of $\mathrm{CR}, \mathrm{PR}$, and MR patient's serums (upper figure A). No augmentation was observed in the cases of PD patients (lower figure A). These aperiodic waves were studied by time series analysis using the Wolfram Mathematica program which plotted Ab3 titer at the points $(\mathrm{X}(\mathrm{i}(\mathrm{n}), \mathrm{X}(\mathrm{i}(\mathrm{n}+2)))$ where $\mathrm{i}(\mathrm{n}+2)-\mathrm{i}(\mathrm{n})=7$ days is the time delay. $\mathrm{i}(\mathrm{n})$ : the date of the nth data point. $\mathrm{X}(\mathrm{i}(\mathrm{n}))$ : the concentration of Ab3 on $\mathrm{i}(\mathrm{n})$. Figure 2B: The phase portrait of the Ab1paratactic idiotope augmented as indicated by the Ab3 waves in Figure 2A resembles Lorenz's chaotic attractor. A chaotic attractor was not observed in the case of non-responders (NC and PD) for Pritumumab immuno-therapy. CR: complete Remission, PR: partial remission, MR: moderate remission, NC: nochange , and PD: partial tumor development. 


\section{Open Access Journal of Cancer \& Oncology}

\section{Application of CLN-IgG/Pritumumab against COVID-19 Contagions}

Many virus contagions utilize the vimentin network regardless of their entry mechanisms or the specific receptor they use on the cell surface. Vimentin is a scaffold for virus infectivity (e.g. HIV, Norovirus, CMV, HPV, SARS-CoV) [39-43]. Author reported the possibility of prionogenicity of vimentin to form prion-amyloid under mechanical stress, and vimentin's configurational change from $\alpha$ - helices to $\beta$-sheets is how cancer/tumor cells adapt to severe mechanical stresses [9]. Vipidam might contribute to prion-conduit [44] for its transmission of a stress-trope Chagrin to the host immune surveillance system. Furthermore author presents here a plausible mechanism of tumor regression by means of the repetitive administration of CLN-IgG/Pritumumab (Figure 1 and Figure 2). It indicated that the modulation of PIVIEMT with CLN-IgG/Pritumumab blocked the vipidam conduit followed by the attenuation of hypersensitive PIEZ01/2 leading to reprogramming the cancer stem cells. Application of CLN-IgG/Pritumumab against COVID-19 contagion is also expected to block its infectivity by shutting down the vipidam conduit in the vimentin network which will be able to reverse PIVIEMT discordance to PIVIEMT accordance.

\section{Discussion}

COVID-19 caused acute respiratory disease [45], cardiovascular damage [46], severe immune suppression [47], and autoimmune diseases [48] (e.g. Guillian-Barré syndrome (GBS), Sjögren's syndrome (SS), Rheumatoid Arthritis (RA)) in the patients. Therefore imminent and suitable vaccinization is necessary to defend the people from virus infection on this planet at least with anxiolytic effect. It is noteworthy about autoimmune responses in COVID-19 patients. COVID-19 was associated with Sjögren's syndrome in which anti-vimentin antibodies were conspicuously expressed. A part of vipidam motif was the one of epitopes recognized by natural auto-antibodies in the patient [49]. This finding suggested that vipidam might contribute to prion-conduit for its transmission of a stress-trope Chagrin to the host immune surveillance system [50]. Whether autoantibodies are pathogenic or protective on onset of autoimmune diseases is still controversial. Rather in tumorigenesis, cancer patient's recovery is well influenced by autoimmune response with the autoantibodies of the tertiary lymphoid structures (TLS) in tumor microenvironment (TME) [51]. From the aspect of the dichotomy of cancer stem cell development [52], in some occasions stem cells and their niche cells show the opposite functions on tumorigenesis. It seems that sustenance of neural stem cells should be prioritized for living things. Therefore immune response is a double-edged sword.

\section{Conclusion}

From the aspect of the PIVIEMT scheme, an application of CLN-IgG/Pritumumab was the critical intervention against tumorigenesis of brain tumors. Author provided here an application of CLN-IgG/Pritumumab toward EMT/MET modulation as a potent coordinator of antibody-directed COVID-19 vaccine basing on a conceptual rationale how antivipidam antibody therapy could be worthwhile for ending the COVID-19 pandemic via antibody-directed vaccination basing upon PIVIEMT accordance.

\section{Acknowledgement}

All labors of scientific research and time to prepare this manuscript were solely supported by HIHIMSA Foundation

\section{Conflict of Interest}

Authors have no competing interest concerning this article.

\section{References}

1. Robbiani DF, Gaebler C, Muecksch F, Lorenzi JCC, Wang $\mathrm{Z}$, et al. (2020) Convergent antibody response to SARSCoV-2 in convalescent individuals. Nature 584(7821): 437-442.

2. Zost SJ, Gilchuk P, Case JB, Binshtein E, Chen RE, et al. (2020) Potently neutralizing and protective human antibodies against SARS-CoV-2. Nature 584(7821): 443449.

3. Beudoin-Bussières G, Laumaea A, Anand SP, Prévost J, Gasser R, et al. (2020) Decline of humoral responses against SARS-CoV-2 spike in convalescent individuals. mBio 11(5): e02590.

4. Nagai M, Narita J, Watanabe K, Endo M, Ochiai C, et al. (1996) Clinical Effect of CLN-IgG on Glioma and Its Correlation with the Induction of Antianti-Idiotypic Antibody in the Serum. In: Nagai M [eds.] Brain Tumor Research and Therapy, Springer-Verlag, Tokyo, pp: 381387.

5. Hagiwara H, Aotsuka Y (1996) Structural analysis of anti-cancer antibody CLN-IgG and anti-idiotypic antibody idio-No 3 for the study of idiotope image transmission: an insight into antigen- specific human monoclonal antibody therapy. In: Nagai M [eds.] Brain Tumor Research and Therapy, Springer-Verlag, Tokyo, pp: 371-379.

6. Glassy MC, Hagiwara H (2009) Summary analysis of the 


\section{Open Access Journal of Cancer \& Oncology}

preclinical and clinical results of brain tumor patients treated with Pritumumab. Hum Antibodies 18(4): 127137.

7. Hugwil AV (2013) The meaning of the anti-cancer antibody CLN-IgG (Pritumumab) generated by human $\mathrm{x}$ human hybridoma technology against the cyto-skeletal protein, vimentin, in the course of the treatment of malignancy. Med Hypoth 81(3): 489-495.

8. Lin S, Sun C, Teng N, Yang W, Zhou L, et al. (2015) Chaperone-like effect of a scFv antibody on the folding of human muscle creatine kinase. Prot Eng Des Sele 26(8): 523-531.

9. Hugwil AV, Glassy MC (2018) Prionogenicity of vimentin surmized from the sequelog of anti- idiotypic antibodies toward the paratope of malignant-associated autologous anti-vimentin antibody CLN-IgG (Pritumumab). $\mathrm{Br} \mathrm{J}$ Cancer Res 1(1): 113-125.

10. Satoh K, Hata M, Takahara S, Tsuzaki H, Yokota H, et al. (2006) A novel membrane protein, encoded by the gene covering KIAA0233, is transcriptionaly induced in senile plaque- assiciated astrocytes. Brain Res 1108(1): 19-27.

11. Wang L, Zhou H, Zhang M, Liu W, Deng T, et al. (2019) Structure and mechanogating of the mammalian tactile channel PIEZO2. Nature 573: 225-229.

12. Chesler AT, Szczot M, Bharucha-Goebel D, Čeko M, Donkervoort S, et al. (2016) The role of Piezo2 in human mechanosensaton. N Engl J Med 375(14): 1355-1364.

13. Sun Y, Li M, Liu G, Zhang X, Zhi L, et al. (2020) The function of Piezo1 in colon cancer metastasis and its potential regulatory mechanism. J Cancer Res Clin Oncol 146(5): 1139-1152.

14. Pietra AD, Mikhailov N, Giniatullin R (2020) The emerging role of mechanosensitive Piezo channel in Migraine pain. Int J Mol Sci 21(3): 696.

15. Strouhalova K, Přechová M, Gandolovičová A, Brábek J, Gregor M, et al. (2020) Vimentin intermediate filaments as potential target for cancer treatment. Cancers 12(1): 184.

16. Ivaska J (2011) Vimentin: central hub in EMT induction? Small GTPase 2(1): 51-53.

17. Richardson AM, Havel LS, Koyen AE, Konen JM, Shupe J, et al. (2018) Vimentin is required for lung adenocarcinoma metastasis via heterotypic tumor cell-cancer-associated fibroblast interactions during collective invasion. Clin Cancer Res 24(2): 420-432.
18. Schoumacher M, Goldman RD, Louvard D, Vignjevic DM (2010) Actin, microtubles, and vimentin intermediate filaments cooperate for elongation of invadopodia. J Cell Biol 189(3): 541-556.

19. McDonald-Hyman C, Mutler JT, Loschi M, Thangavelu G, Saha A, et al. (2018) The vimentin intermediate filament network restrains regulatory cell suppression of graftversus-host- disease. J Clin Invest 128(10): 4604-4621.

20. Havel LS, Kline ER, Salgueiro AM, Marcus AI (2015) Vimentin regulates lung cancer cell adhesion through a VAV2-Rac1 pathway to control focal adhesion kinase activity. Oncogene 34(15): 1979-1990.

21. Dubois F, Bénard M, Jean-Jacques B, Schapman D, Roberge $\mathrm{H}$, et al. (2020) Investigating tunneling nanotubes in cancer cells: Guidelines for structural and functional studies through cell imaging. BioMed Res Inter, Article ID: 2701345.

22. Lavenus SB, Tudor SM, Ullo MF, Vosatka KW, Logue JS (2020) A flexible network of vimentin intermediate filaments promotes migration of amoeboid cancer cells through confined environments. J Biol Chem 295(19): 6700-6709.

23. Lee CH (2019) Reversal of epithelial-mesenchymaltransition by natural anti-inflammatory and proresolving lipids. Cancers 11(12): 1841.

24. Danielsson F, Kristen $M$, Araújo HC, Lautenschläger F, Gad AKB (2018) Vimentin diversity in health and disease. Cells 7(10): 147.

25. Chen X, Wanggou S, Bodalia A, Zhu M, Dong W, et al. (2018) A feedforward mechanism mediated by mechanosensitive ion channel PIEZO1 and tissue mechanics promotes glioma aggression. Neuron 100(4): 799-815.

26. Felice DD, Alaimo A (2020) Mechanosensitive PIEZO channels in cancer: focus on altered calcium signaling in cancer cells and in tumor progression. Cancers 12(7): 1780 .

27. Solis AG, Bielecki P, Steach HR, Sharma L, Harman CCD, et al. (2019) Mechanosensation of cyclical force by PIEZO1 is essential for innate immunity. Nature 573(7772): 6974.

28. Gunin AG, Golvbtzova NN (2020) Role of the mechanosensitive protein Piezo1 in age- dependent changes in the number of fibroblasts and blood vessels in human skin. Adv Gerontol 32(3): 357-363.

29. Ridone P, Pandzic E, Vassalli M, Cox CD, Macmillan A, 


\section{Open Access Journal of Cancer \& Oncology}

et al. (2020) Distribution of membrane cholesterol organization impairs the activity of PIEZO1 channel clusters. J Gen Physiol 152(8): e201912515.

30. Chen CW, Deivasikamani V, Ludlow MJ, DeVecchis D, Kalli AC, et al. (2020) Genetic variants of PIEZO1 associated with COVID-19 fatality. medRxiv.

31. Li J, Hou B, Tumova S, Muraki K, Bruns A, et al. (2015) Piezo1 integration of vascular architecture with physiological force. Nature 515(7526): 279-282.

32. Velasco-Estevez M, Mampay M, Boultin H, Chaney A, Warn P, et al. (2018) Infection augments expression of mechanosensing PIEZ01 channels in amyloid plaquereactive astrocytes. Front Agi Neuro 10: 332.

33. Lee CH (2019) Reversal of epithelial-mesenchymaltransition by natural anti-inflammatory and proresolving lipids. Cancers 11(12): 1841.

34. Asep S, Hening H, Gema PS, Gigih S, Widya M, et al. (2017) Anticancer activity of Jatrophane an isolated compound from jatropha gossypifolia plant against hepato cellular cancer cell HEP G2 1886. Biomed Parmacol J 10(2): 667673.

35. Fröhlich JK, Stein T, daSilva LA, Biavatti MW, Tonussi CR, et al. (2017) Anti-nociceptive and anti-inflammatory activities of the jatropha isabelli dichloromethane fraction and isolation and quantitative determination of Jatrophane by UFLC-DAD. Pharma Biol 55(1): 12151222.

36. Hugwil AV, Glassy MC (2017) Idiotypic antibody network regarding malignant cell regression in the brain tumor patients treated with the natural human monoclonal antibody, Pritumumab. Integr Cancer Bio Res 1(1): 003.

37. Sautès-Fridman C, Petitprez F, Calderaro J, Fridman WH (2019) Tertiary lymphoid structures in the era of cancer immunotherapy. Nat Rev Cancer 19(6): 307-325.

38. Li Z, Paulin D, Lacolley P, Colletti D, Agbulut O (2020) Vimentin as a target for the treatment of COVIV-19. BMJ Open Resp Res 7(1): e000623.

39. Fernández-Ortega C, Raḿrez A, Casillas D, Poneque T, Ubieta R, et al. (2016) Identification of vimentin as a potential therapeutic target against HIV infection. Viruses 8(6): 98.

40. Hyde JL, Gillespie LK, Mackenzie JM (2012) Mouse norovirus 1 utilizes the cytoskeleton network to establish localization of the replication complex proximal to the microtubule organizing center. J Virol 86(8): 4110-4122.
41. Miller MS, Hertel L (2009) Onset of human cytomegalovirus replication in fibroblasts requires the presence of an intact vimentin cytoskeleton. J Virol 83(14): 7015-7028.

42. Schäfer G, Graham LM, Long DM, Blumenthal MJ, Marusic MB, et al. (2017) Vimentin modulates infectious internalization of human papillomavirus 16 pseudovirions. J Virol 91(16): e00307-e00317.

43. Yu YT C, Chien S C, Chen I T, Lai T, Tsay Y G, et al. (2016) Vimentin is critical for the cell entry of SARS-CoV. J Biomed Sci 23:14.

44. Shorter J, Lindquist S (2005) Prions as adaptive conduits of memory and inheritance. Nat Rev Gene 6: 435-450.

45. Wec AZ, Wrapp D, Herbert AS, Mauer DP, Haslwanter D, et al. (2020) Broad neutralization of SARS-related viruses by human monoclonal antibodies. Science 369(6504): 731-736.

46. Wu L, O'kane AM, Peng H, Bi Y, Motriuk-Smith D, et al. (2020) SARS-CoV-2 and cardiovascular complications: from molecular mechanisms to pharmaceutical management. Biochem Pharma 178: 114114.

47. Remy KE, Mazar M, Striker DA, Ellebedy AH, Walton $\mathrm{AH}$, et al. (2020) Severe immunosuppression and not a cytokine storm characterize COVID-19 infections. JCI insight 5(17): e140329.

48. Monreal E, de la Maza SS, Fernández-Velasco JI, Natera-Villabra E, Rita CG, et al. (2020) The impact of immunosuppression and autoimmune disease on severe outcomes in patients hospitalized with COVID-19. J Clin Immunol 41(2): 315-323.

49. Li YH, Gao YP, Dong J, Shi LJ, Sun XL, et al. (2018) Identification of a novel autoantibody against selfvimentin specific in secondary Sjögren's syndrome. Arthritis Res Ther 20(1): 30.

50. Hugwil AV (2019) Is tumorigenesis an abiogenesis? J Cancer Oncol 3(1): 000139.

51. Qui J, Keyer B, Lin ZT, Wu T (2018) Autoantibodies as potential biomarkers in breast cancer. Biosensors 8(3): 67.

52. Hugwil AV (2018) On the dichotomous aspect of cancer stem cell. J Cancer Oncol 2(2): 000123. 